\title{
Comparative study between intravaginal misoprostol and extra- amniotic instillation of ethacridine lactacte for second trimester abortion
}

\author{
Suryaprakash Jagdevappa Karande ${ }^{1 *}$, Meena Shantanu Gunjotikar ${ }^{2}$
}

\author{
${ }^{1}$ Department of Obstetrics and Gynecology, Ashwini Rural Medical College, Hospital and Research Centre, Kumbhari, \\ Solapur, Maharashtra, India \\ ${ }^{2}$ Department of Obstetrics and Gynecology, Gunjotikar Nursing Home, Solapur, Maharashtra, India
}

Received: 08 April 2017

Accepted: 02 May 2017

\section{*Correspondence: \\ Dr. Suryaprakash Jagdevappa Karande, \\ E-mail: sjkarande2000@yahoo.co.in}

Copyright: ( ) the author(s), publisher and licensee Medip Academy. This is an open-access article distributed under the terms of the Creative Commons Attribution Non-Commercial License, which permits unrestricted non-commercial use, distribution, and reproduction in any medium, provided the original work is properly cited.

\begin{abstract}
Background: The methods of terminating pregnancy in the first trimester are simple, safe and effective. Factors like lack of knowledge about availability of MTP services, ignorance, denial of pregnancy, fear of society may account for decrease in number of first trimester abortions. The aims of the present study were to compare the efficacy, induction abortion interval and side effects of intravaginal misoprostol with extra amniotic installation of ethacridine lactate for second trimester abortion.

Methods: 60 women coming to MTP clinics requesting second trimester pregnancy termination between 12 to 20 weeks were selected. Detail history and examination was carried out in each patient. They divided into two groups, Group A (30) intravaginal misoprostol 400 initially followed by 400 micrograns every 6 hourly if required. Group B (30) extra-amniotic $0.1 \%$ ethacridine lactate $150 \mathrm{cc}$.

Results: In Group A success rate was $100 \%$ while in Group B it was $76.66 \%$, which is highly statistically significant $(\mathrm{P}<0.01)$. Mean I - A interval in Group A was $14.58+5.25$ hours was highly significantly less than in Group B, it was $33.91+3.97$ hours $(\mathrm{p}<0.0001)$. In Group A complete abortion has occurred in 28 cases $(93.33 \%)$ and in Group B in 12 cases $(52.17 \%)$.

Conclusions: We conclude that, as compared to extra-amniotic instillation of ethacridinelactate intravaginal misoprostol is the preferred regimen in second trimester abortion because of its high efficacy, shorter induction abortion interval, high incidence of completeness of abortion, low incidence of side effects and better tolerance by the patient.
\end{abstract}

Keywords: Abortion, Induction abortion interval, Second trimester, Side effect

\section{INTRODUCTION}

There is no doubt that widespread use of contraceptives prevent unwanted pregnancies. However due to absence of an ideal contraceptive and far from optional usage rate, millions of unwanted pregnancies are terminated every year in India. The Medical Termination of Pregnancy Act was passed in 1972 in India. Since then a large number of women have availed the facility of safe abortion in government and private hospitals. While massive national and worldwide initiatives are being taken to reduce morbidity and mortality from unsafe abortion, the fact remains that abortion is an important cause of maternal mortality. As a cause of maternal mortality, abortion 
remains one of the most important neglected health issues in India. ${ }^{1}$ What is even unmeasurable is the amount of morbidity associated with abortions. The morbidity and mortality of any abortion procedure increases with the gestational age of the pregnancy.

The method of terminating pregnancy in the first trimester are simple, safe and effective. They are associated with fewer complications, negligible morbidity and are almost devoid of maternal mortality. Even then, the demand for midtrimester termination of pregnancy exists. Several factors like lack of knowledge about availability of MTP services, ignorance, denial of pregnancy, fear of society may account for decrease in number of first trimester abortions. In addition to this, antenatal diagnosis of congenital anomalies, teratogenic effects of drugs used in early pregnancy, late diagnosis of associated disease that may be a threat to the wellbeing of woman or infant increases the need for second trimester abortion. From last few decades, with reasonable success, various methods of termination have been tried for second trimester. ${ }^{2}$

Procedures for inducing abortions, if not properly carried out can impair women's health through a variety of complications that may occur at the time of abortions or may affect the future course of pregnancies. An ideal method should be safe, easy, effective and associated with less complications, morbidity, mortality and short induction - abortions interval.

Extra - amniotic installation of Ethacridine Lactate has been the tradional method for termination of pregnancy in India for more than three decades. While the procedure is notable for its safety, its efficacy is far from satisfactory with high failure rates, long induction-abortion intervals and complications.

The Prostaglandins from the E group have a higher ratio of cervical ripening to uterine contractility and are preferred to Prostaglandins of the F group. Among these Misoprostol is a Prostaglandin E1Analogure that has recently been used by a number of authors for second trimester abortions singly or with Mifepristone RU 486, Methotrexate, Gemeprost, Ethacridine lactate. Misoprostol is being (off label) used for termination of pregnancy in between 13 and 20 weeks, in different doses and by different routes with better results. ${ }^{3-6}$

The aims and objectives of the present study are to compare the efficacy, induction abortion interval and side effects of intravaginal misoprostol with extra amniotic installation of ethacridine lactate for second trimester abortion.

\section{METHODS}

60 women coming to MTP clinics in our Y.C.R. hospital, Latur requesting second trimester pregnancy termination between 12 to 20 weeks were included in the study after informed and written consent was taken. A patient was excluded if she has a prior myometrial incision, bronchial asthma, cardiovascular, renal, hepatic diseases, severe anaemia. Detail history and examination was carried out in each patient. All the routine investigations were carried out in the form of $\mathrm{Hb} \%$, urine albumin and sugar, blood group and Rh typing. USG was done to know the exact gestational age, cardiac activity and placental localization.

\section{Inclusion criteria}

- Patients with gestational age between 12-20 weeks requesting for MTP.

- Patients with gestational age between 12-20 weeks who required termination of pregnancy due to congenital anomalies or some other causes.

\section{Exclusion criteria}

- Previous uterine scar.

- Patients with any medical disorder. E.g. Heart disease, severe anaemia, renal disease, bronchial asthma, hepatic diseases, known hypersensitivity to drug.

60 Patients were divided into two groups.

- Group A (30): Intravaginal Misoprostol 400 micrograms initially followed by 400 micrograns every 6 hourly if required. Maximum dose $1200 \mu \mathrm{gm}$

- Group B (30): Extra - amniotic 0.1\% Ethacridine lactate $150 \mathrm{cc}$

\section{Technique of intravaninal administration of misoprostol (Group A)}

2 tablets of $200 \mu \mathrm{gm}$ Misoprostol were placed deep in the posterior fornix, next to cervix during manual vaginal examination after cleaning the perineal region with antiseptic solution. Patient received no premedication. The patient was advised to lie on her back for $45 \mathrm{~min}$. The vital signs of the patient were monitored. Progression of abortion was assessed by cervical examination at the time of each drug administration. Occurrence of adverse reactions like pain in abdomen requiring analgesics, fever, nausea, vomiting, and diarrhoea were recorded.

Every 6 hourly per speculum and per vaginal examination was done. If on examination cervix was found open further doses of Misoprostol were not administered and spontaneous expulsion was awaited. If no progression of abortion has occurred at 6 hourly examination, 2 tablets of $200 \mu \mathrm{gm}$ misoprostol were repeated every 6 hourly till maximum dose $1200 \mu \mathrm{gm}$ has reached.

The failure of treatment was defined as the failure of abortion to take place within 48 hours after initial administration of misoprostol. 


\section{Technique of extra-amniotic installation ofethacridine lactate (Group B)}

Patient was asked to empty the bladder and lithtomy position was given. No anesthesia was given. After painting, draping and retracting posterior vaginal wall with Sim's speculum, the anterior lip of cervix was held with vulsellum. A Foleys catheter number 16 was introduced through cervical canal. Then the catheter was negotiated into extra ovular space gradually beyond the internal os. The bulb of the Foley's catheter was inflated with $30 \mathrm{ml}$ of sterile normal saline or distilled water. After a little pull on the catheter it was folded and tied with sterile gauze piece. Extra-amniotic $0.1 \%$ Ethacridine lactate $150 \mathrm{cc}$ instillation was done.

Patient was later shifted towards where she was carefully monitored for vital signs and untoward effects. The onset, duration and frequency of uterine contractions was noted. Failure of treatment was defined as the failure of abortion to take place within 48 hours after initial administration of Ethacridine lactate. Failure cases were managed with 20 units of oxytocin in $500 \mathrm{ml}$ of $5 \%$ dextrose.

\section{Statistical analysis}

The data obtained from the study were organized and analyzed statistically. Descriptive statistics such as mean, SD and percentage was used. Chi-square test for categorical data and student ' $t$ ' test for continuous data was used to compare the differences in the two groups. A p- value of less than 0.05 was considered significant.

\section{RESULTS}

The maximum number of cases in Group A were between 26-30 years of age $(40 \%)$ and in Group B were between 21-25 years of age $(56.66 \%)$ presented in Table 1.

Table 1: Age distribution.

\begin{tabular}{|lllll|}
\hline $\begin{array}{l}\text { Age group } \\
\text { (years) }\end{array}$ & Group A & Group B \\
\hline $15-20$ & 5 & 16.66 & 5 & 16.66 \\
\hline $21-25$ & 7 & 23.33 & 17 & 56.66 \\
\hline $26-30$ & 12 & 40 & 6 & 20 \\
\hline $31-35$ & 6 & 20 & 2 & 6.66 \\
\hline
\end{tabular}

This table shows that $60 \%$ of cases belong to $17-20$ weeks of gestation in both Group A and Group B presented in Table 2 .

Table 2: Gestational age distribution (in weeks).

\begin{tabular}{lllll|} 
Gestational & Group A & \multicolumn{2}{c}{ Group B } \\
age (weeks) & Cases & \% & Cases & \% \\
\hline $\mathbf{1 2}-\mathbf{1 6}$ & 12 & 40 & 12 & 40 \\
\hline $\mathbf{1 7}-\mathbf{2 0}$ & 18 & 60 & 18 & 60 \\
\hline
\end{tabular}

Majority of patients in Group A and Group B were of Para $2(36.66 \%)$ and $(23.33 \%)$ respectively presented in Table 3 .

Table 3: Distribution of parity.

\begin{tabular}{|lllll|}
\hline & Group A & \multicolumn{2}{l|}{ Group B } \\
\hline Parity & Cases & \% & Cases & \% \\
\hline Primigravida $(\mathrm{p} 0)$ & 8 & 26.66 & 6 & 20 \\
\hline Para 1 $(\mathrm{p} 1)$ & 3 & 10 & 6 & 20 \\
\hline Para 2 $(\mathrm{p} 2)$ & 11 & 36.66 & 7 & 23.33 \\
\hline Para 3 $(\mathrm{p} 3)$ & 6 & 20 & 6 & 20 \\
\hline Para $\geq 4(\mathrm{p} 4)$ & 2 & 6.66 & 5 & 16.66 \\
\hline
\end{tabular}

\section{Efficacy (success rate)}

The procedure was said to be effective when patient had aborted within 48 hours after the first dose of Misoprostol or after initial instillation of Ethacridine lactate.

Table 4: Efficacy (success rate).

\begin{tabular}{|lllll|}
\hline \multirow{2}{*}{ Outcome } & Group A & \multicolumn{2}{c|}{ Group B } \\
\hline Successful & Cases & \% & Cases & \% \\
\hline Failed & 30 & 100 & 23 & 76.66 \\
\hline Total & 0 & 0 & 7 & 23.33 \\
\hline
\end{tabular}

$\chi^{2}=5.8, \mathrm{p}<0.01$

Above table shows that in Group A all the 30 cases $(100 \%)$ were successfully aborted in 48 hours. Where as in Group B 23 cases out of 30 (76.66\%) were successfully aborted within 48 hours.

The success rate in Group A (100\%) was highly significantly more than Group B $(76.66 \%)(\mathrm{P}<0.01)$ presented in Table 4.

\section{Induction abortion (I-A) interval}

It is the time interval from dose of Misoprostol or instillation of Ethacridine lactate till abortion occurred either complete or incomplete (Retained products or retained placenta).

Table 5: Induction abortion (I-A) interval.

\begin{tabular}{|llll|} 
Group & Successful cases & \multicolumn{2}{l|}{ I - A Interval (hrs) } \\
\hline A & 30 & $14.58 \pm 5.25$ & $9-27.30$ \\
\hline B & 23 & $33.91 \pm 3.97$ & $28-42$ \\
\hline
\end{tabular}

The table shows mean I-A interval of Group A was $14.58+5.25$ hours and of Group B was 33.91+3.97 hours.

The successful cases I-A interval was highly significantly more in Group A compared to Group B $(\mathrm{t}=14.71$, $\mathrm{p}<0.0001)$ presented in Table 5. 


\section{Completeness of abortion}

The complete abortion is defined as the passage of fetus and placenta without operative procedure or assistance of any other drugs.

Table 6: Completeness of abortion in women who aborted successfully.

\begin{tabular}{|lllll|}
\hline \multirow{2}{*}{ Type of abortion } & \multicolumn{2}{c}{ Group A } & \multicolumn{2}{c|}{ Group B } \\
\hline Complete abortion & 28 & 93.33 & 12 & 52.17 \\
\hline Retained products & 1 & 3.33 & 8 & 34.78 \\
\hline Retained placenta & 1 & 3.33 & 3 & 13.04 \\
\hline Total & 30 & 100 & 23 & 100 \\
\hline$\chi^{2}=16.87, p<0.0001$ & & & & \\
\hline
\end{tabular}

$\chi^{2}=16.87, \mathrm{p}<0.0001$

Above table shows that maximum no. of cases (93.33\%) of complete abortion was in Group A. In Group B complete abortion was in $(52.17 \%)$ of patients. 1 case of retained product in Group A $(3.33 \%)$ whereas 8 cases in Group B $(34.78 \%)$. 1 case $(3.33 \%)$ of retained placenta in Group A while 3 cases $(13.04 \%)$ in Group B. The successful cases completeness of abortion was highly significantly more in Group A $(93.33 \%)$ as compared to Group B $(52.17 \%)(\mathrm{p}<0.0001)$ presented in Table 6.

In present study haemorrhage is defined as blood loss due to abortion which adversely affects the general condition of the patient evidenced by rise in pulse rate and fall in blood pressure and those requiring blood transfusion.

In the above table, cases in which retained products and retained placenta had occurred manual evacuation was done. In Group B for haemorrhage manual evacuation and conventional curettage was done in 2 cases $(6.66 \%)$.

Table 7: Complications.

\begin{tabular}{|lllll|}
\hline Type of & \multicolumn{2}{c}{ Group A } & Group B \\
complications & No. & \% & No. & \% \\
\hline Retained products & 1 & 3.33 & 8 & 26.66 \\
\hline Retained placenta & 1 & 3.33 & 3 & 10 \\
\hline Haemorrhage & 0 & 0 & 2 & 6.66 \\
\hline
\end{tabular}

Complication rate was highly significantly less in Group A (2 cases or $6.66 \%)$ as compared to Group B (11 cases or $36.66 \%)(\mathrm{P}<0.01)$ presented in Table 7.

In present study fever was categorized in two groups:

- $\quad$ Mild fever Body temperature between $37.5-37.8^{\circ} \mathrm{C}$

- High grade fever Body temperature between 39.4$40.5^{\circ} \mathrm{C}$

Vomiting was categorized in two groups:

- Milder type: vomiting that does not produce impairment of health or restrict the normal activities of the women,
- Severe type: vomiting which has got deleterious effect on maternal health and / or restrict the normal activities.

Most of the fever and vomiting in Group A were mild and resolved without further complications. While in Group B 2 cases $(6.66 \%)$ were of high grade fever and severe vomiting. The side effects in Group A were not statistically significantly different than that in Group B (P $>0.05$ ) presented in Table 8 .

\section{DISCUSSION}

In this prospective study patients in both groups were comparable with respect to age, parity and gestational age. In the present study in both group $\mathrm{A}$ and $\mathrm{B}$, the procedure was said to be effective when patient had aborted within 48 hours after the induction of abortion. In the present study, success rate was $100 \%$ in Group A, while in Group B it was $76.66 \%$ and it was highly significantly more in Group A compared to Group B $(p<0.0001)$. Present results are exactly similar to the results obtained by both the studies done by Dickinson JE et al. ${ }^{7}$ The regimen of Misoprostol used in present study is exactly similar to that of Dickinson et al. ${ }^{8}$

Bhathena, Allhabadia found success rates $92 \%$ and $98 \%$ respectively. ${ }^{9,10}$ But in our study success rate was $76.66 \%$. This could be possibly due to a difference of definition of success rate. The cut-off point for a failed case in these studies was 72 hours, while in our study it was 48 hours. When this cut-off point in our study was extended up to 72 hours the success rate in Group B reached $93.33 \%$ (28 cases). Thus, present results about efficacy are comparable with the results obtained by Bhathena and Allahabadia. Bebbington et al found $87 \%$ success rate with $400 \mathrm{mcg}$ misoprostol every 4 hours with induction abortion interval of 19.6 hours. ${ }^{11}$ Agarwal S reported $97 \%$ success rate with $200 \mathrm{mcg}$ misoprostol every 4 hours, with average induction abortion interval of 14.3 hours. $^{12}$

The mean induction abortion interval in Group A was $14.58 \pm 5.25$ hours. Our results about induction abortion interval in Group A are comparable with the results obtained by Dickinson et al, Bugalho A et al. ${ }^{7,8,13}$ In Group B the mean induction abortion interval was 33.91 \pm 3.97 hours. Present results about induction abortion interval in Group B are comparable with the results obtained by Allahbadia, Bathena and Shukla et al. ${ }^{9,10,14}$

In case of retained placenta and retained products, manual evacuation was done, while in case of haemorrhage conventional curettage was done. Thus, in Group A manual evacuation was done in 2 cases $(6.66 \%)$ while in Group B only manual evacuation was done in 9 cases and 2 cases manual evacuation was combined with conventional curettage because of haemorrhage. These 2 cases in Group B were given blood transfusion. 
Complication rate was highly significantly less in Group A (2 cases or $6.66 \%)$ as compared to Group B (11 cases or $36.66 \%)(\mathrm{P}<0.01)$. According to Elsheikh $\mathrm{A}$ et $\mathrm{al}^{15}$ in his study retained products in $9.2 \%$ retained placenta in $8.2 \%$ cases. According to Bugahlo A et al complete uterine evacuation has occurred in $76 \%$ cases, manual evacuation in $24.12 \%$ and conventional curettage in $3.07 \% .^{13}$ In Group B planned evacuation was done 9 cases $(30 \%)$. According to Bathena et al ethacridine group planned evacuation was done in 152 cases out of $207(73 \%){ }^{9}$

Most of the fever and vomiting in Group A were mild and resolved post-partum without further complications. While in group B, 2 cases $(6.66 \%)$ were of high grade fever and severe vomiting and these were managed by giving antipyretics, antiemetics and IV fluids. The side effects in Group A were not statistically significantly different than that in Group B $(\mathrm{P}>0.05)$. Side effects observed by Jain and Mishell using misoprostol are Fever $(11 \%)$, vomiting (4\%), diarrhea $(4 \%)$ and by Herabutya et al are fever (41\%), vomiting (15\%), diarrhea $(20 \%) .{ }^{16,17}$

Side effects observations made by Allhabadiaet al by using ethacridine lactate alone are fever (6\%), vomiting $(2 \%)$, rigors $(5 \%)$, haemorrhage $(2 \%){ }^{10}$

\section{CONCLUSION}

We conclude that, as compared to extra-amniotic instillation of Ethacridine lactate, $400 \mu \mathrm{gm}$ of vaginal Misoprostol initially followed by $400 \mu$ gm every 6 hourly if required (Maximum dose up to $1200 \mu \mathrm{gm}$ ), is the preferred regimen in second trimester abortion because of its high efficacy, shorter induction abortion interval, high incidence of completeness of abortion, low incidence of side effects and better tolerance by the patient.

Funding: No funding sources

Conflict of interest: None declared

Ethical approval: The study was approved by the Institutional Ethics Committee

\section{REFERENCES}

1. Nagrath A, Malhotra N, Singh M. A passage through abortion. New Delhi: Jaypee. Brothers Medical Publishers; 2001:3-8.

2. Nagaria T, Sirmor N. Intravaginal misoprostol for termination of second trimester pregnancy. J Obstet Gynecol India. 2007;57:435-8.

3. Wong KS, Ngai CS, Yeo EL, Tang LC, Ho PC. A comparison of two regimens of intravaginal misoprostol for termination of second trimester of pregnancy: a randomized comparative trial. Hum Reprod. 2000;15:709-12.
4. Herabutya Y, Chanrachakul B, Punyavachira P. Vaginal misoprostol in termination of second trimester of pregnancy. J Obstet Gynecol Res. 2000;26:121-5.

5. Pongsatha $\mathrm{S}$, Tongsong T. Second trimester pregnancy termination with $800 \mathrm{mcg}$ vaginal misoprostol . J Med Assoc Thai. 2001;84:859-63.

6. Herabutya Y, Chanrachakul B, Punyavachira P. Second trimester pregnancy termination: A comparison of 600 and 800 micrograms of intravaginal misoprostol. J Obstet Gynecol Res. 2001;27:125-8.

7. Dicknson JE, Evans SF. The Optimization of intravaginal Misoprostol dosing schedules in second trimester pregnancy termination. Am J Obstet Gynecol. 2002;186(3):470-4.

8. Dickinson JE, Evans SF. A comparison of oral Misoprostol with vaginal Misoprostol administration in second trimester pregnancy termination for fetal abnormality. Obstet Gynecol. 2003;101(6):1294-9.

9. Bhathena RK, Sheriar NK, Walvekar VR, Guillebaud J. Second trimester pregnancy termination using extraamniotic ethacridine lactate. Br J Obstet Gynaecol. 1990;97:1026-9.

10. Gautam A. Comparative study of mid trimester termination of pregnancy using hypertonic saline, Ethacridine lactate, prostaglandin analogue and iodinesaline. J Indian Med Assoc. 1992;90(9):237-9.

11. Bebbington MW, Kent N, Lim K, Gagnon A, Delisle $\mathrm{MF}$, Tessier $\mathrm{F}$ et al. A randomized controlled trial comparing two protocols for use of misoprostol in midtrimester pregnancy termination. Am J Obstet Gynaecol. 2002;187(4):853-7.

12. Agrawal S, B Chaturvedi. An experience with misoprostol in second trimester MTP. J Obstet Gynae India. 2002;52(5):52-4.

13. Bugalho, Bique C, Bergstrom S. Pregnancy interruption by vaginal Misoprostol. Obstet Gynaec Invest. 1993;36:226-9.

14. Shukla S, Sapre S, Olyai P. Midtrimester pregnancy termination with Ethacridine lactate. J Indian Med Assoc. 1984;82(12):432-4.

15. Elsheikh A, Antsaklisv A. Use of Misoprostol for termination of second trimester pregnancy. Arch Gynecol Obstet. 2001;265(4):204-6.

16. Jain JK, Mishell DR. A comparison of intravaginal Misoprostol with prostaglandin E2 for termination of second trimester pregnancy. $\mathrm{N}$ Engl $\mathrm{J}$ Med. 1994;331(5):290-3.

17. Herabutya Y, Chanrachakul B, Punyavachira P. Vaginal Misoprostol in termination of second trimester pregnancy. J Obstet Gynecol Res. 2000;26(2):121-5.

Cite this article as: Karande SJ, Gunjotikar MS.

Comparative study between intravaginal misoprostol and extra-amniotic instillation of ethacridine lactacte for second trimester abortion. Int J Reprod Contracept Obstet Gynecol 2017;6:2575-9. 